\title{
PEER-REVIEW METHODOLOGY WITH EXERCISES SUPERVISED IN CLASS
}

\author{
S. Blanco, J.J. Arribas, J.M. Goicolea, J.C. García, F. Gabaldón \\ Technical University of Madrid (SPAIN)
}

\begin{abstract}
In this work we present a methodology to perform peer-assessment activities in courses of the first years of the engineering curriculum whose evaluation is based mainly on the resolution of problems, and it is convenient that the tasks to be evaluated are carried out in class in a supervised way. The aim of the project we present here was to implement a peer-to-peer correction tool, ensuring that the student's work is done individually in class and leaving the peer-assessment process off-class, using, in each of the phases of the activity, the following set of computer applications: auto-multiple-choice open source program, LibreOffice Calc, google-forms applications, google mail and home-made shell scripts in a Linux platform. We apply this methodology to a workshop offered to students in order to help them to prepare a final exam in the Degree of Civil and Territorial Engineering (U.P.M.). The attendance was voluntary and did not affect the final grade. The results show that the population of students who attended the workshop obtained better grades than those who did not attend, increasing both the average grade and the percentage of passes. This methodology of support for students has proven to be a useful tool to facilitate the acquisition of competences associated with an engineering subject whose evaluation lies largely in the resolution of problems.
\end{abstract}

Keywords: Large students groups, Skills assessment, Basic subjects in engineering and architecture.

\section{INTRODUCTION}

Peer assessment, where students grade assignments based on a teacher's benchmarks, is a methodology that allows the student to reflect on their actual level of knowledge in a subject and, thanks to the correction rubrics, identify those aspects whose domain is key to be able to successfully achieve the desired competences. This activity help to close the gap between the receipt of feedback and its application [1] because peer-tutoring leads the students to rehearse, evaluate and hence improve their own understanding of the topic [2]. However, when peer-assessment is an evaluable activity it is essential to guarantee that the student is the one who has done the work individually, being necessary that the tasks to be fulfilled are performed in class in a supervised manner, especially when the activities to be evaluated are exercises of the courses of the engineering curriculum with a specific solution, and where aspects such as creativity are less important. In this work we present a methodology to implement peer-assessment with exercises performed in class in a straight-forward manner without necessarily increasing teacher workload.

\section{METHODOLOGY}

The objective of performing a peer-assessment guaranteeing that the student's work is done individually in class is achieved by using, in each of the phases of the activity, a set of computer applications that are summarized in Fig. 1.

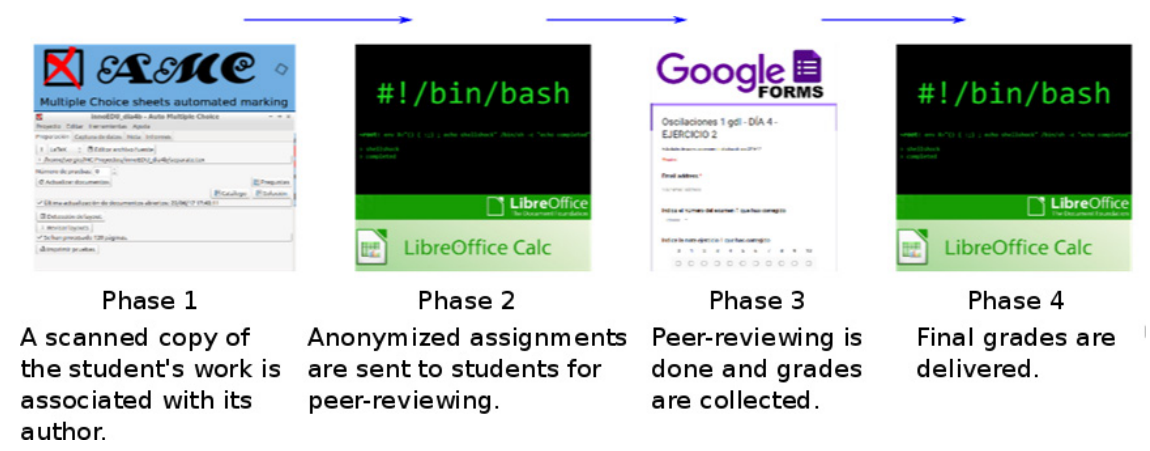

Figure 1. Description of the phases of the activity. 
In Phase one, the student performs the activity using a set of papers, given by the teacher, with identification marks that allows the program Auto-Multiple-Choice [3] to collect and relate a scanned copy of each work and the author who has done it. Once the student identification is removed from the scanned copy of the work, in phase two every assignment anonymized is sent to four students for peer-reviewing alongside with the teacher's benchmarks. In phase three the students grade their peers and in phase four the final marks (as the average value of the grades each work has received) are delivered. The key point of the whole process is the ability of the program Auto-Multiple-Choice to relate, in an effortless and easy way, the scanned copies of the work done and the student who has done each exercise. We describe now with more detail each one of the phases we have just summarised.

\subsection{Phase 1: Relate the student and the scanned copy of her work}

The exercise to solve is defined and printed by using the Auto-Multiple-Choice program that allows to generate copies of the exercise, each individualized by a numerical code, in which the statement is included in page two, there is a space for the student identification in page five and the remaining space is meant to solve the exercise. In total, three sheets of paper are given to each student, which are schematized in Fig. 2, whose pages are numbered from one to six.

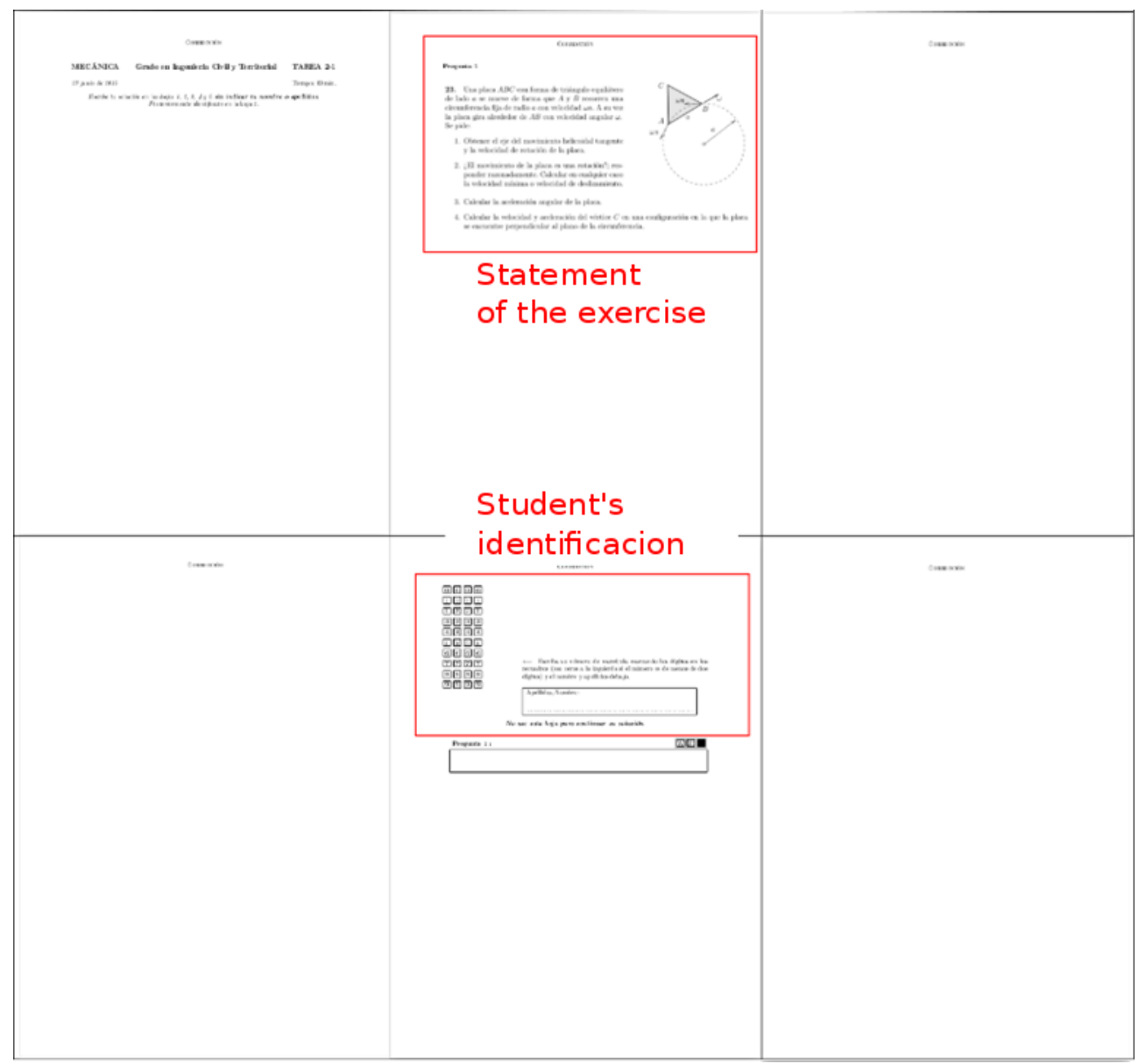

Figure 2. Description of the AutoMultipleChoice output.

Once the students have done the exercise, all the sheets of paper are scanned and, using the AutoMultiple-Choice program again, a scanned copy of each handwritten exercise is obtained in pdf format along with its association with the student who has done it. This association is saved in a data spreadsheet like the one presented in Fig. 3, where the variable Examen refers to the problem copy solved and the variable nummat to the registration number of the student who has done it (red lines cover the student's data). 


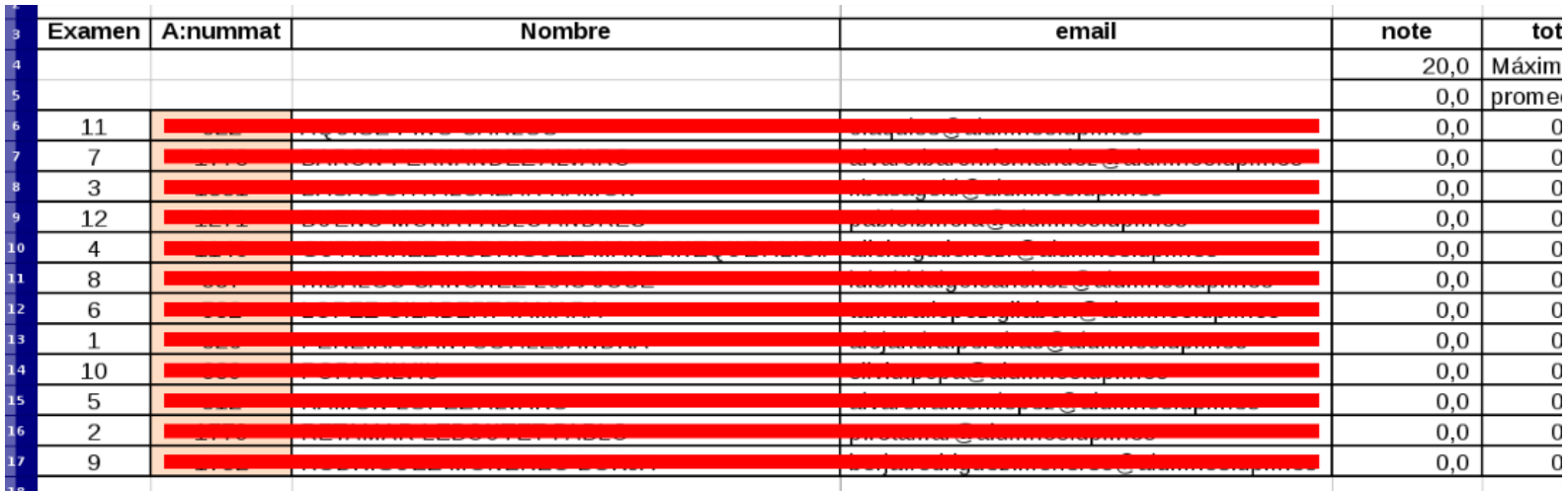

Figure 3. Association of the solved problem copy and the student who has done it.

\subsection{Phase 2: Sending the anonymized versions of the exercises for peer- review}

By using the relationship between "scanned problem solutions" and "student author of the solution", four exercises are assigned to each student to correct. Afterwards, with a script written in the shell of a Linux machine, page five (where lies the students' identification, see Fig. 2) of the scanned copies is extracted to make them anonymous and, finally, each problem copy is sent to peer-assessment by the students together with the solution of the exercise and a correction rubric (see Fig. 4 for an example).

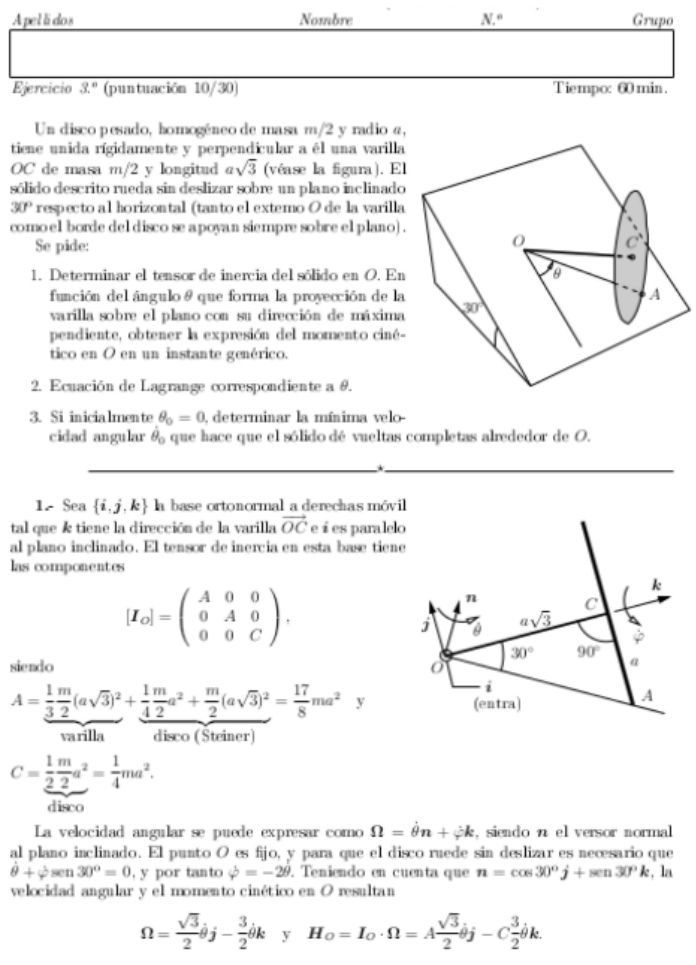

Rúbrica de corrección. Día 7, Ejercicio 2.

\begin{tabular}{|l|c|}
\hline INDICADOR & Puntuación \\
\hline Interpreta correctamente la velocidad de rotación del sólido. & 0.5 \\
\hline Identifica que por rodar sin deslizar sólo hay un grado de libertad. & 0.5 \\
\hline Calcula correctamente la velocidad angular en función de $\dot{\theta}$ & 1.0 \\
\hline $\begin{array}{l}\text { Al cal cular el tensor de inercia } \mathbf{I}_{O} \text { usa una base formada por sus } \\
\text { direcciones principales e identifica que es diagonal con simetría } \\
\text { cilíndrica }\end{array}$ & 0.5 \\
\hline Calcula correctamente el tensor de inercia $\mathbf{I}_{O}$ & 1.0 \\
\hline $\begin{array}{l}\text { Expresa correctamente el momento cinético en } 0 \text { (I } O \text { y } \Omega \text { deben estar } \\
\text { en la misma base) }\end{array}$ & 0.5 \\
\hline $\begin{array}{l}\text { En el apartado } 2 \text { calcula correctamente la energía cinética (bien como } \\
\text { sólido con punto fijo o bien aplicando el teorema de König). }\end{array}$ & 1.0 \\
\hline En el apartado 2 define correctamente el potencial de los pesos & 1.0 \\
\hline En el apartado 2 calcula correctamente el potencial de los pesos & 1.0 \\
\hline $\begin{array}{l}\text { En el apartado } 2 \text { conoce la expresión de la ecuación del movimiento } \theta \text { a } \\
\text { partir de la función lagrangiana. }\end{array}$ & 0.5 \\
\hline En el apartado 2 calcula correctamente la ecuación del movimiento $\theta$ & 0.5 \\
\hline $\begin{array}{l}\text { En el apartado } 3 \text { razona correctamente que la condición que se expresa } \\
\text { implica que cuando } \theta=\pi \text { el sólido no debe tener energía cinética. }\end{array}$ & 1.0 \\
\hline $\begin{array}{l}\text { En el apartado } 3 \text { identifica que se conserva la energía mecánica y lo usa } \\
\text { igualar el valor de la energía mecánica en el instante en que lo sabe } \\
\text { todo }(\theta=\pi) \text { y el instante del que le pregunta }(\theta=0 \text { en } t=0)\end{array}$ & 1.0 \\
\hline $\begin{array}{l}\text { Se realiza un desarrollo claro del ejercicio con una presentación limpia y } \\
\text { ordenada }\end{array}$ & 1.0 \\
\hline
\end{tabular}

NOTAS:

- La columna "Puntuación" se refiere al valor que se le da al indicador asociado dentro del ejercicio. No debes limitarte a sumar los indicadores conseguidos por el alumno, también deberás ponderar negativamente aquellos errores de concepto que veas (tendrás valores positivos y negativos).

- No puntúes como "indicador conseguido/indicador no conseguido". Puedes ser flexible y dar una puntuación intermedia.

- Si la solución resulta una expresión muy compleja y observas que no

Figure 4. Example of solution along with its correction rubric (in Spanish).

\subsection{Phase 3: Collection of peer assessment grades}

The students' evaluations are collected by using a google form in which the student must provide, for each of the exercises she/he has to assess, the problem copy number the student is evaluating and the mark she/he has judged to give (see Fig. 5). 


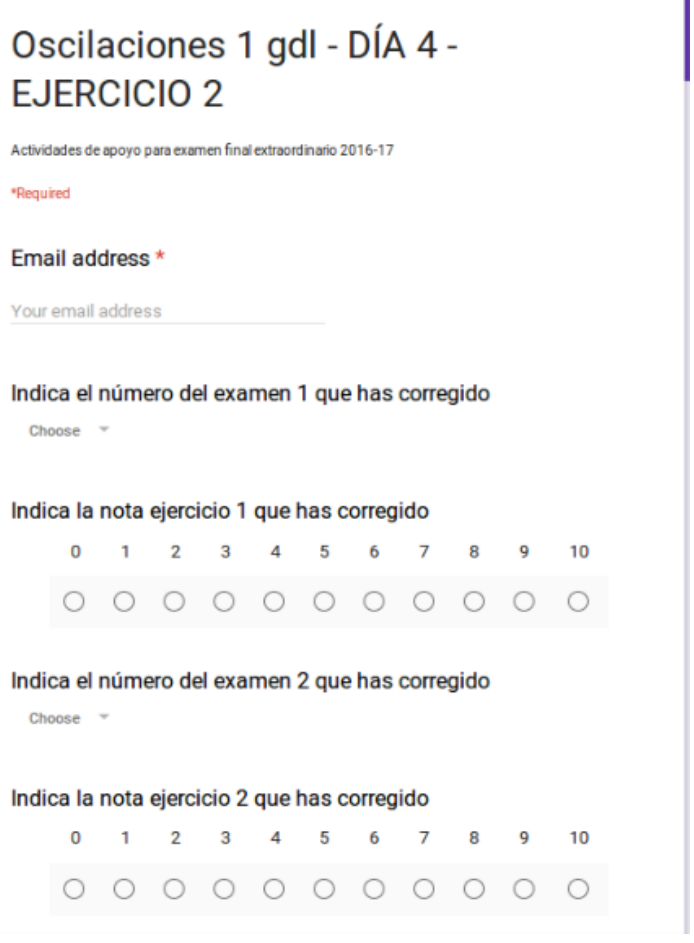

Figure 5. Grade collection form (in Spanish)

\subsection{Phase 4: Calculation and deliver of final grades}

Finally all the qualifications associated with a solved exercise are grouped, the average of the notes is calculated and, by means of a script in the shell of a Linux machine, the mark is automatically sent to the student who has solved the exercise.

\section{RESULTS}

The results presented in this work correspond to a workshop offered to students who, having failed the ordinary exam of a subject of the degree in Civil and Territorial Engineering (U.P.M.), expressed their desire to submit to the extraordinary exam. During two weeks a two-hour daily workshop was held in which two examination exercises were worked every day. The evaluation of the activity was among the students themselves, in order to test the methodology developed in the project. The attendance was voluntary and did not affect the final grade, being able the students to attend those sessions they wanted.

\subsection{Quantitative description}

We describe, previously to the analysis of the results, the two study populations we have considered: the notes of those students who, having submitted to the extraordinary examination, did attend a workshop session (SiTaller population) and those who did not (NoTaller population). Table 1 and Figs. 6 and 7 summarize the characteristics of both populations.

Table 1. Summary of population data.

\begin{tabular}{c|c|c}
\hline & NoTaller Population & SiTaller Population \\
\hline Number of members & 63 & 14 \\
\hline Minimum grade value & 0 & 0.3 \\
\hline Maximum grade value & 7.1 & 5.6 \\
\hline Average grade value & 2.1 & 3.3 \\
\hline Deviation & 1.5 & 1.4 \\
\hline \hline
\end{tabular}




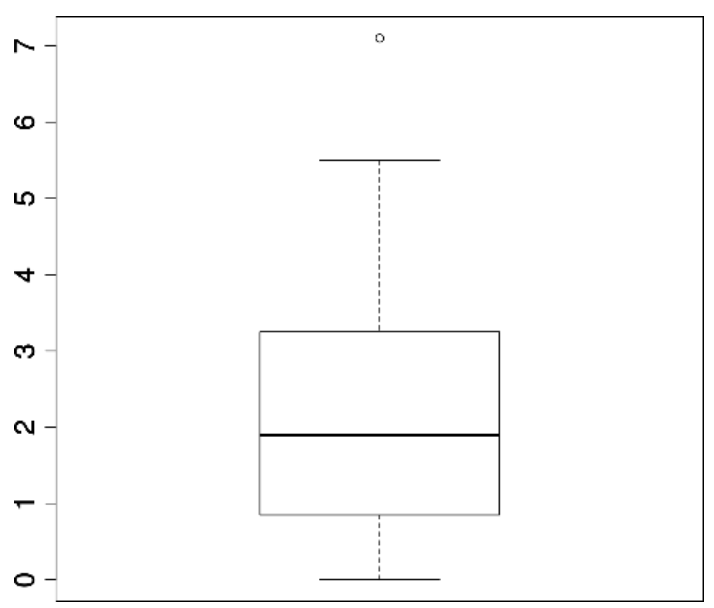

Figure 6. Box plot NoTaller population

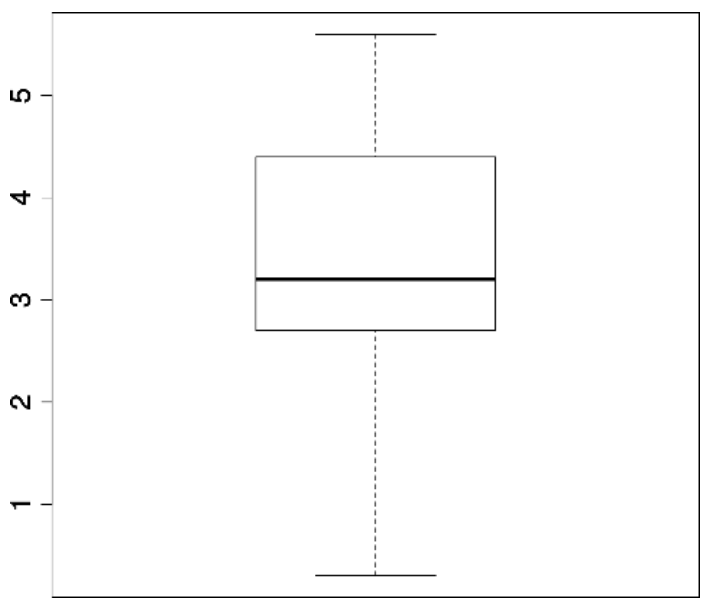

Figure 7. Box plot SiTaller population

The results show that the population of students who attended the workshop obtained better grades than those who did not attend, increasing both the average grade and the percentage of passes. The percentage of students that passed the exam in the population who attended the workshop is $21.1 \%$, compared to $5.1 \%$ in the population who did not (see Fig. 8). If we compare the students who have improved their grade in the extraordinary exam with respect to their ordinary exam, we see that $57.1 \%$ of the population who attended the workshop has improved their grade, compared to $38.1 \%$ of the population who did not attend the workshop (see Fig. 9).

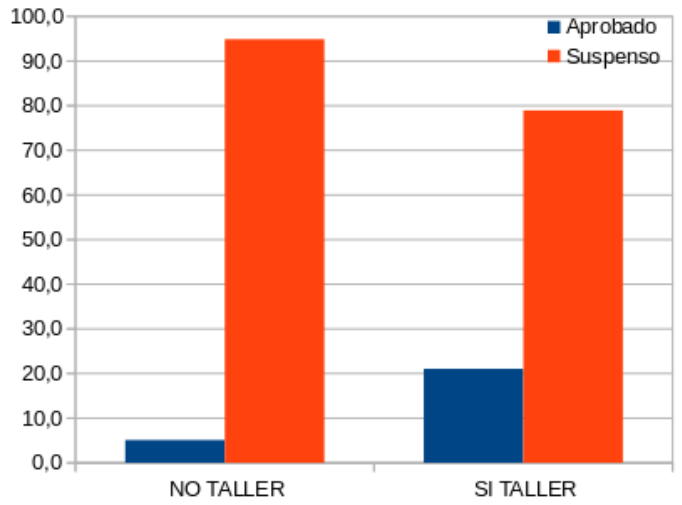

Figure 8. Students approved and suspended

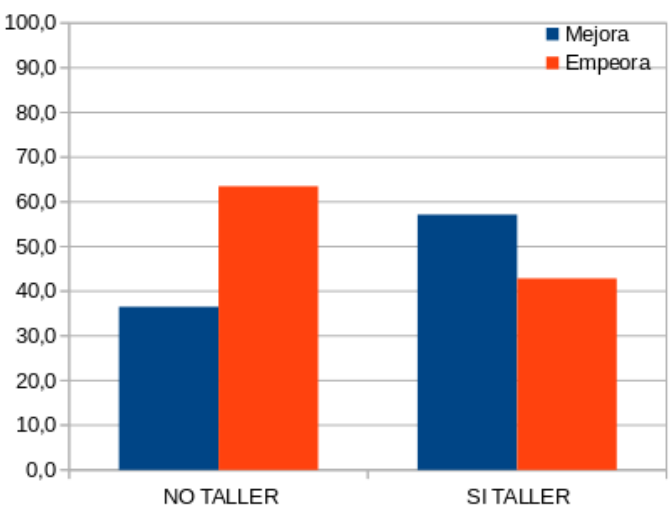

Figure 9. Note variation between ordinary and extraordinary exams

\subsection{Student perception}

Once the workshop finished, a survey was sent to the participants in order to evaluate the perception the students had about the methodology (usefulness, improvement of self-knowledge, reduction of anxiety facing the exam, organizational aspects, etc....). We got only four answers to the survey with highly appreciative opinions. In the authors' viewpoint, such a small number of answers preclude to establish conclusions. However, we would like to include the comments that the students did at the end of the survey:

- It was a very complete workshop, we reviewed all the subjects of the course during two weeks and it was of great help at the time of organizing the study.

- I think everything was very well thought out. It was done during the exam period and attendance was not mandatory. It also did not occupy much time each day. Emphasis was placed on resolution strategies.

- I find the use of the correction rubric and the correction of exams to other colleagues very useful. In addition, the difficulty of the exercises was similar to that of the exam and each workshop was an opportunity to test yourself as if you were in a real exam. 
- Very useful to define and identify the concepts that are used in the resolution of the exercises.

- For me one of the most useful things was the correction rubrics. They helped me a lot to know what was expected of me in the exam and what percentage of the concepts I really knew.

- I do not know if there was one because I did not find it, but a calendar with the topics that will be discussed in each session would be very useful since they do not go in the same order as the course syllabus.

- The only thing I regret about the workshop is how little it lasted. The problems of each session were very well chosen, but being the period of exams and not being able to attend every day, I missed some things. The teacher sent us the documents when we could not go, but still I would have liked to go more times.

\section{CONCLUSIONS}

This methodology of support for students has proven to be a useful tool to facilitate the acquisition of competences associated with an engineering subject whose evaluation lies largely in the resolution of complex problems.

However, the use of several computer tools means that the presented methodology is not easily applicable. Therefore, and as future work, it is proposed to implement all processes external to the Auto-Multiple-Choice program (spreadsheets, survey forms, emails) in the Google Aps Script environment and, in this way, be able to be offered to the university community.

\section{ACKNOWLEDGEMENTS}

This work has been developed in the framework of the project "Proyecto de Innovación Educativa IE1617.0402 2016-17" supported by the Technical University of Madrid.

The authors are also grateful for the help of the Agustín de Betancourt Foundation.

\section{REFERENCES}

[1] N., David, A. Thomson, and C. Breslin. "Rethinking feedback practices in higher education: a peer review perspective." Assessment \& Evaluation in Higher Education 39.1: 102-122 (2014).

[2] R., Roscoe, and M. Chi. "Tutor Learning: The Role of Explaining and Responding to Questions." Instructional Science 36: 321-350 (2008).

[3] A. Bienvenüe. "Automatic Multiple Choice, Multiple Choice sheets automated marking," Project website: http://home.gna.org/auto-qcm/. 